\title{
Econder
}

\author{
International Academic Journal
}

[Econder], 2019, 3 (2): 240/251

Ekonomi Güven Endeksi ve Bileşik Göstergeler: Birleşik Krallık Örneği

$\&$

\section{Economic Setlement Index and Compound Indicators: Case of UK}

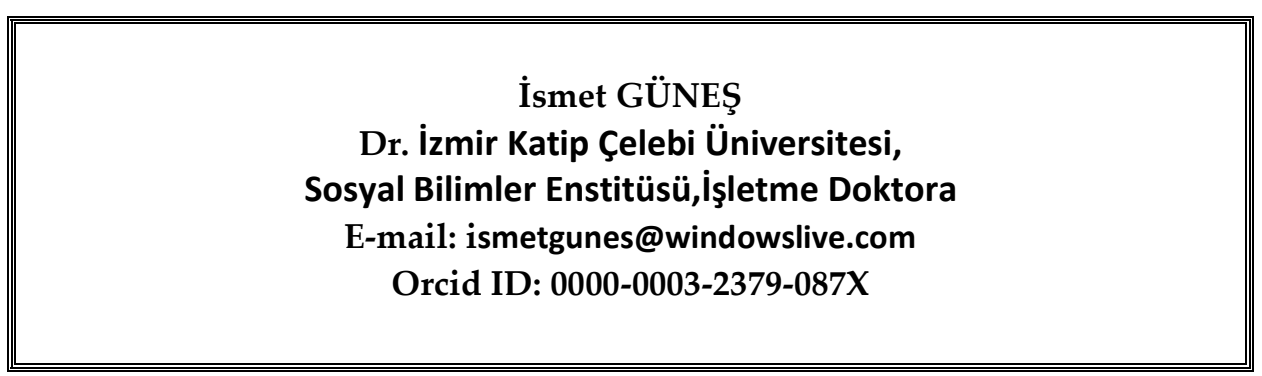

Makale Bilgisi / Article Information

Makale Türü / Article Types : Araştırma Makalesi / Research Article

Geliş Tarihi / Received : :22.12.2019

Kabul Tarihi / Accepted $\quad$ : 30.12 .2019

Yayın Tarihi / Published : 30.12 .2019

Yayın Sezonu : Aralık

Pub Date Season : December

Atıf/Cite as: Güneş. İ. (2019). Ekonomi Güven Endeksi ve Bileşik Göstergeler: Birleşik Krallık Örneği, Econder International Academic Journal , 3 (2) , 240-251 .

İntihal /Plagiarism: Bu makale, en az iki hakem tarafından incelenmiş ve intihal içermediği teyit edilmiştir. / This article has been reviewed by at least two referees and scanned via a plagiarism software.

Copyright (C) Published by Hayrettin KESGINGÖZ- Karabuk University, Karabuk, 78050 Turkey. All rights reserved. 


\title{
Ekonomi Güven Endeksi ve Bileşik Göstergeler: Birleşik Krallık Örneği
}

Öz

Bu çalışma, Avrupa Komisyonu tarafından hesaplanan iktisadi duyarlılık göstergelerinin ve Ekonomik Kalkınma ve İş birliği Örgütü tarafından hesaplanan bileşik öncü göstergelerin oluşumunu incelemektedir. Çalışmanın amacı, bazı ülkeler için Avrupa Komisyonu İktisadi Duyarlılık Göstergelerinin güncel tesadüfi performansını değerlendirmek ve iktisadi eylemlerde döngüleri önceden tahmin edebilecek duyarlılık göstergeleri oluşturma ihtimallerini araştırmaktır. Özel olarak da aşağıdaki konular; Bileşen dizilerinin seçilmesi: ülkeler için standart veya en iyi performans gösteren bileşenler, Bileşen dizilerinin ağırlık andırılması: bireysel bileșenler veya kümeler için farklı veya eșit ağırlıklar, Döngüsel genişliklerin normalleştirilmesi ve bileşen dizilerinin düzleştirilmesi, Bileşen dizilerinin (hızlı-çok çabuk) ulaşılabilirliği ve revizyonları tartışılmıştır.

Anahtar Kelimeler: Güven Endeksi, İktisadi Yönelim Anketi, Avrupa Komisyonu, Bileşen Dizileri, İktisadi Duyarlilik

\section{Economic Setlement Index and Compound Indicators: Case of UK}

\begin{abstract}
This study examines the formation of indicators of economic sensitivity calculated by the European Commission and composite leading indicators calculated by the Organization for Economic Development and Cooperation. The aim of the study is to evaluate the current random performance of the European Commission's Economic Sensitivity Indicators for some countries and to investigate the possibility of generating sensitivity indicators that can predict cycles in economic actions. In particular, the following issues were discussed ; Selection of component arrays: standard or best performing components for countries, Weighting of component arrays: different or equal weights for individual components or clusters,Normalization of cyclic amplitudes and flattening of component arrays and Availability of component sequences (fast-to-quick) and revisions.
\end{abstract}

Keywords: Confidence Index, Business Tendency Survey, European Commission, Component Sequences, Economic Sensitivity 


\section{Giriș}

Birleşik Krallık ile sınırlandırılan çalışmada İktisadi Yönelim Anketi uygulayan pek çok kuruluş, bir takım anket dizesi seçmekte ve bunları tek bir konjonktürel bileşen veya güven göstergesinde birleştirmektedir. Buradaki amaç, yanlış alarm riskini düşürmek ve konjonktürel göstergeye diğer bileşenlerinden daha iyi öngörü ve takip özellikleri kazandırmaktır.

Tek bir bileşik göstergeyle bir araya getirilmiş bir grup göstergenin, belirli bir zaman dilimi içerisinde diğer bileşenlere kıyasla daha güvenilir olması gerektiği, iş döngüsü ile alakalıdır. Her döngü kendi ünik özelliklere sahiptir ve diğer döngülerle ortak niteliklere sahiptir. Ancak, belirli bir zaman dilimi içindeki tek bir döngüsel dalgalanma, aktivitenin bütününü açıklamaz. Bireysel göstergelerin performansı, belirli döngülerin arkasındaki sebeplere bağlı olacaktır. Bazı göstergeler bir döngüde daha iyi performans gösterecektir. Bu yüzden döngüsel değişimlerin pek çok olası nedeni ve muhtemel bütün göstergeleri bir grup olarak kullanabilmek için işaretler gereklidir.

$\mathrm{Bu}$ çalışma, Avrupa Komisyonu tarafından hesaplanan iktisadi duyarlılık göstergelerinin ve Ekonomik Kalkınma ve İşbirliği Örgütü tarafından hesaplanan bileşik öncü göstergelerin oluşumunu incelemektedir. Çalışmanın amacı, bazı ülkeler için Avrupa Komisyonu İktisadi Duyarlılık Göstergelerinin güncel tesadüfi performansını değerlendirmek ve iktisadi eylemlerde döngüleri önceden tahmin edebilecek duyarlılık göstergeleri oluşturma ihtimallerini araştırmaktır.

$\mathrm{Bu}$ çalışma Birleşik OECD Bileşik Öncü Göstergeler ile sınırlandırılmıştır. Performanslar, toplam sanayi üretimine karşı hem dönüm noktalarında hem de bütün bir döngü boyunca (çapraz korelasyon), iktisadi aktivitenin bir temsilcisi olarak değerlendirilmiştir. Bu sonuçlar aynı ülkeler için OECD Bileşik Öncü Göstergelerinin performansları ile karşılaştırılmıştır.

Avrupa komisyonu sisteminde standart bir bileşik dizisi kullanılmaktadır. Bu sizi büyük oranda ticari veya tüketici yönelim anketlerinden alınan niteliksel verilere dayanmaktadır. Avrupa komisyonu ekonomik duyarlılık göstergeleri aşağıdaki bileşen dizilerini bir araya getirir:

- $\quad$ Sanayi güven göstergesi

- İmar güven göstergesi

- Tüketici güven göstergesi

- Hisse değer endeksi 
Burada bireysel bileşen dizilerinin döngüsel performansına odaklanmaktadır. Bundaki amaç en iyi öncü özelliğe sahip olan bileşikleri ortaya çıkarmaktır. Bu değerlendirmeden elde edilen sonuçlar ülkelere-özel bileşik dizilerinin seçiminde ve alternatif ekonomik duyarlılık göstergeleri oluşturulmasında temel olarak kullanılmıştır. Her ülke için alternatif ekonomik duyarlılık göstergeleri oluşturulmuş ve 4. Bölümde değerlendirilmiştir.

Bileşik dizelerinin ağırlığının etkisi de 4. Bölümde incelenmiştir. Farklı ağırlıklar güncel Avrupa komisyonu sisteminde kullanılmaktadır. Güncel Avrupa komisyonu ekonomik duyarlılık göstergelerinin performansları, bireysel bileşik dizilerinin eşit ağırlığa sahip aynı ekonomik duyarlılık göstergeleri ile kıyaslanarak değerlendirilmiştir.

Avrupa komisyonu sisteminde ülkeler çapında standart bileşik diziler kullanılmaktadır, buna karşın OECD sisteminde her ülke için dönüm noktalarında en iyi öncü performansa sahip diziler mevcuttur. 5. Bölümde OECD Bileşik Öncü Göstergelerinin oluşumu için kullanılan bileşik dizileri araştırılmış ve Avrupa komisyonu sisteminde kullanılan bileşikler ile kıyaslanmıştır.

Bileşik indeks veya güven indeksinin hesaplanması için temel adımlar 6 . Bölümde belirtilmiş, OECD ve Avrupa komisyonu tarafından uygulanan metodlardaki farklılıklar tartışılmıştır. Daha özel olarak, güncel Avrupa komisyonu sisteminde kullanılan normalleş(tir)me metodu tartışılmıştır. Bu metot, aydan aya ortalama değişimlerinin eşit olabilmesi için her bileşik serisini standartlaştırmaktadır. Ancak bu metot, önceden hususi bir düzeltme işlemi yapılmadıkça, bileşik indeksin döngüsel hareketlerindeki daha düzensiz dizilere daha az ağırlık vermektedir. Güncel Avrupa komisyonu sisteminde, bileşik dizelerine düzeltme işlemi uygulanmamaktadır ve bileşenlerin hareketli ortalama ile düzeltilmesinin etkisi OECD sisteminde kullanılmaktadır.

Aşırı revizyonların olmaması ve zamanlaması, iyi döngüsel göstergelerin bir gerekliliğidir. Ve bu özellikler de aynı zamanda, bileşik göstergelerin oluşumu için bileşen dizilerinin kümelenmesi ile bağlantılı olarak 6. Bölümde tartışılmıştır. Son olarak, her bölümden ana sonuçlar bir özet halinde sunulmuştur ve daha iyi öncü performanslar sağlayan alternatif ekonomik duyarlılık göstergeleri oluşturma olasılıkları ile ilgili bir sonuç verilmiştir. 


\section{Alternatif İktisadi Duyarlılık Göstergelerinin Oluşturulması ve Performans1}

Bölüm üçte Elde edilen sonuçlar gösteriyor ki, her ülke için en iyi bileşenleri seçerek ve birleştirerek döngüsel performansı geliştirmek mümkündür. alternatif ekonomik duyarlılık göstergelerinin farklı setlerinin tarihsel süreçteki performansı tablo 3 te gösterilmiştir.

Mevcut Avrupa komisyonu ekonomik duyarlılık göstergeleri yukarda da ifade edildiği gibi bileşen serilerinin kümelendirilmesi için farklı ağırlıklar kullanmaktadır. Eğer yalnızca en iyi bileşenler seçilirse ve bir araya getirilirse, o zaman bileşenlere eşit ağırlıklar vermek mantıklı alabilir ve alternatif ekonomik duyarlılık göstergeleri farklı bileşenler için eğit ağırlıklar ile oluşturulur.

\section{Birleşik Krallık: Alternatif İktisadi Duyarlılık Göstergeleri}

Birleşik Krallık için değerlendirilen altı alternatif ESI, aşağıdaki bileşenleri içermektedir.

- ESI: Ekonomi Duyarlılık Endeksi

- ICI: Sanayi güven göstergesi

- CCI: Construction güven göstergesi

- SPI: Hisse fiyat endeksi

- CSCI Tüketici güven göstergesi

- EC ESI: Avrupa komisyonu ekonomik duyarlılık göstergeleri

İlk dört alternatif duyarlılık göstergesinin değerlendirmeleri hem 1970-99 hem de 1976-99 döneminde gerçekleştirilir. Bu, sadece hisse fiyat endeksi verileri 1970'e kadar mevcut iken, diğer bileşenler için veriler 1974-1977 arasında başladığı için yapılır. 1976-99 dönemine ait sonuçlar alternatif duyarlılık göstergelerinin performansını daha iyi temsil etmektedir ve aşağıda yorumlanmıştır.

ESI1, mevcut EC ESI ile aynı dört bileşeni içerir, sadece ağırlıklandırma sistemi iki gösterge arasında farklıdır. Bu potansiyel duyarlılık göstergesinin 1977-99 dönemindeki döngüsel performansı, tüm dönüm noktalarında ortalama 3 ay, dip noktalarda ortalama 5 ay ve zirvelerde 1 aydır. Bu performans, tüm dönüm noktalarında ortalama 1 ay lead ile daha rastlantısal bir görünüm sergileyen EC ESI'ye kayıtlı performanstan biraz daha iyidir. EC ESI'de yer alan bileşenlerin üçünün farklı kombinasyonlarına sahip olan iki alternatif duyarlılık göstergesi (ESI2 ve ESI3), ESI1 ile aynı performansı gösterir. 
Referans serisine karşı en uzun lead'lere sahip en iyi bileşenlerden sadece ikisi birleştirildiğinde daha da iyi bir performans elde edilir. Bu bileşenlerin farklı kombinasyonları, ESI4, ESI5 ve ESI6 duyarlılık göstergelerine dâhil edilmiştir. En iyi performans, endüstriyel güven göstergesini ve hisse fiyat endeksini içeren ESI5 için kayıtlıdır. Bu gösterge 10 aya yakın tüm dönüm noktalarında ortalama bir lead, dip noktalarda ortalama 11 ay ve zirve noktalarında 7 ayın üzerinde bir kurşun gösterir.

Bu sonuçlar, Birleşik krallık için mevcut EC ESI'den daha iyi öncü performansa sahip alternatif ESI'lerin yapılabileceğini göstermektedir. Sadece EC ESI'de yer alan bileşenlerin eşit ağırlıklandırma sistemini tanıtarak daha iyi öncü performansa sahip bir gösterge (ESI1) vermiştir. Ancak en iyi performans, üç bileşenden sadece ikisini referans serisine karşı en uzun lead'ler ile birleştirirken elde edilmiştir.

\section{Her Ülke İçin Standart Özel Bileșenler Seti}

Bileşik bir göstergeye dâhil edilecek bileşen serisinin seçimi için iki farklı strateji kullanılabilir. Ülkeler arasında standart bir gösterge kümesi kullanılabilir veya ülke başına ayrı bir gösterge kümesi kullanılabilir. Ülkeler arasında standart bir gösterge kümesi kullanılması, uluslararası karşılaştırılabilirliği elde etmek için iyi bir yaklaşımdır. Bununla birlikte, bir ülkede iyi performans gösteren döngüsel göstergeler, ekonomik yapıdaki ve istatistiksel sistemdeki farklılıklar nedeniyle bir başkasında iyi çalışmayabilir.

Avrupa komisyonu ekonomik duyarlılık göstergeleri standart bir gösterge kümesi üzerinden hesaplanır. Bununla birlikte, Bölüm 3'te gösterildiği gibi, EC sisteminde kullanılan standart göstergelerin bazıları tüm ülkelerde eşit derecede işe yaramamıştır ve alternatif ülkeye özgü ESI'ler daha iyi lider performansıyla oluşturulabilir.

OECD CLI, her ülke için ayrı ayrı seçilen öncü göstergelere dayanmaktadır. Bu göstergenin performansı, Avrupa komisyonu ekonomik duyarlılık göstergelerinin performansı ile karşılaştırıldı ve sonuçlar OECD CLI'nın lehine sonuçland1.

\section{Birleşik Devletler}

Birleşik Krallık için OECD CLI 9 bileşen içermektedir: 6 iş anketi serisi, 2 finansal seri ve dayanıklı tüketim malları tüketimine ilişkin bir seri (kayıtlı otomobiller).



ECONDER

International Academic Journal

[Issn: 2602-3806]
Cilt / Vol : 3,

Sayı/Issue: 2,

2019 
Yalnızca hisse fiyatı endeksi, EC ESI ile ortak olarak kullanılan bir bileşen serisidir. Altı iş anketi serisinin üçü de Avrupa komisyonu ekonomik duyarlılık göstergesine dâhil edildi, ancak endüstriyel güven göstergesindeki bileşenler olarak (üretim beklentileri, sipariş defterleri ve mamul stokları). Diğer üç anket serisi ise iş ortamı, ihracat beklentileri ve hammadde stokları beklentileridir. Tüm bu diğer anket göstergeleri endüstriyel güven göstergesine dâhil edilen anket serilerinden daha uzun dönüm noktalarına işaret etmektedir.

Finansal serilerdeki (prime banka bonoları) performans, en yüksek periyodu dönüm noktalarında ortalama 17 ay ile, ardından 9 aylık ortalama ile ihracat geleceğine ilişkin anket serileri olarak kaydeder. Bununla birlikte, anket serisinin ikisi, sipariş defterleri ve mamul stokları dönüm noktalarında rastlantısal davranış sergilemektedir. Bu iki seri, Avrupa komisyonu ekonomik duyarlılık göstergesi dâhil olmak üzere endüstriyel güven göstergesindeki bileşenlerdir.

OECD CLI, Avrupa komisyonu ekonomik duyarlılık göstergesi ile karşılaştırıldığında döngüsel dönüm noktalarında biraz daha iyi performans gösterir. Finansal serilerin eklenmesi ve uzun vadeli iş anket serileri bunun arkasındaki ana faktörlerdir. Bununla birlikte, Bölüm 3'te gösterildiği gibi, Avrupa komisyonu ekonomik duyarlılık göstergesinin performansı, bileşenlerin eşit bir ağırlıklandırma sistemi getirilerek geliştirilebilir ve referans serisine karşı en uzun kablolara sahip ağaç bileşenlerinden sadece ikisi birleştirildiğinde daha da iyileştirilebilir.

- ICI: Sanayi güven göstergesi

- CCI: Construction güven göstergesi

- SPI: Hisse fiyat endeksi

- CSCI Tüketici güven göstergesi

EC ESI:: Avrupa komisyonu ekonomik duyarlılık göstergeleri her ülke için ayrı ayrı seçilen öncü göstergelere dayanmaktadır. Bu göstergenin performansı, Avrupa komisyonu ekonomik duyarlılık göstergelerinin performansı ile karşılaştırıldı ve sonuçlar OECD CLI'nın lehine sonuçlandı.

\section{Sonuç}

EC Ekonomik Duygu Göstergesi (ESI) standart göstergelere göre hesaplanırken, OECD Kompozit Lider Göstergesi (CLI) her ülke için ayrı ayrı seçilen öncü göstergelere dayanmaktadır. EC ESI'ye kıyasla OECD CLI lehine iki bölümde sunulan sonuçlar ve $\mathrm{AB}$ ülkelerindeki tahmin kapasitesini 
arttırmak amacıyla EC ESI'nin inşası için alternatif bileşen serisi kombinasyonları, incelenmiştir.

Araştırma her bir ülke için sadece en iyi bileşenleri seçerek ve birleştirerek Avrupa komisyonu ekonomik duyarlılık göstergesinin döngüsel performansını iyileştirmenin mümkün olabileceğini göstermektedir. Avrupa komisyonu ekonomik duyarlılık göstergesi, bileşen serilerinin toplanması için farklı ağırlıklar kullanır. Bununla birlikte, sadece en iyi bileşenler seçilirse ve birleştirilirse, bileşenlere eşit ağırlıklar verilmesi mantıklı olacaktır ve değerlendirilen alternatif ekonomik duyarlılık göstergeleri farklı bileşenler için eşit ağırlıklarla oluşturulmuştur.

Araştırma sonuçları, Avrupa komisyonu ekonomik duyarlılık göstergesinin tahmin performansının, yalnızca bu göstergede en uzun önceliğe sahip bileşenlerin birleştirilmesi halinde, Almanya hariç tüm araştırma yapılan ülkelerde geliştirilebileceğini göstermektedir. İtalya örneğinde, hisse fiyat endeksi hariç tutulursa daha iyi bir alternatif ekonomik duyarlılık göstergesi oluşturulabilir. Bu gösterge, referans serileri ile döngüsel bir ilişki göstermez ve bunun ülkeler arasında standart bir bileşen seti kullanma tehlikesi olduğunu gösterir. Birleşik Krallık sonuçları, sadece Avrupa komisyonu ekonomik duyarlılık göstergesinde yer alan bileşenlerin eşit ağırlıklandırma sistemini tanıtarak daha iyi öncü performansa sahip alternatif bir ekonomik duyarlılık göstergesi verdiğini göstermektedir.

Bileşik bir göstergeye dâhil edilecek bileşen serisinin seçimi için iki farklı strateji kullanılabilir. Ülkeler arasında standart bir gösterge kümesi kullanılabilir veya ülke başına ayrı bir gösterge kümesi kullanılabilir. Ülkeler arasında standart bir gösterge kümesi kullanılması, uluslararası karşılaştırılabilirliği sağlamak için iyi bir yaklaşımdır. Bununla birlikte, bir ülkede iyi performans gösteren döngüsel göstergeler, ekonomik yapıdaki ve istatistiksel sistemdeki farklılıklar nedeniyle bir başkasında iyi çalışmayabilir.

OECD Kompozit öncü Göstergesi (OECD CLI), her ülke için ayrı ayrı seçilen öncü göstergelere dayanmaktadır. Bu göstergenin performans1, Avrupa komisyonu ekonomik duyarlılık göstergesinin performansı ile karşılaştırıldı ve sonuçlar OECD CLI'nın lehine sonuçlandı.

OECD CLI oluşturulması için her ülkede kullanılan bileşen serilerini ve döngüsel özelliklerini inceledik. Sonuçlar, OECD CLI'ye finansal göstergelerin dâhil edilmesinin, Avrupa komisyonu ekonomik duyarlılık göstergesi ile karşılaştırıldığında bu gösterge için elde edilen daha uzun arkasındaki ana 
faktör olduğunu göstermiştir. Birleşik Krallık örneğinde, finansal seri ve uzun vadeli alternatif iş anketi serisinin dâhil edilmesi, OECD CLI'nın Avrupa komisyonu ekonomik duyarlılık göstergesine kıyasla daha iyi performansının arkasındaki ana faktörlerdi.

Bileşik bir endeksin veya bir güven endeksinin hesaplanmasında temel adımlar altıncı bölümde açıklanmıştır ve OECD ve Avrupa Toplulukları Komisyonu (EC) tarafından uygulanan yöntemlerdeki farklılıklar tartışılmıştır. Özellikle, bileşen serilerinin düzgünleştirilmesi, bileşenlerin zamanlaması ve bileşen serilerinde yapılan revizyonlar ve bileşik göstergeler ile ilgili konular incelenmiştir.

OECD sisteminde, bileşen serileri "Döngüsel Baskınlık Ayları" (MCD) hareketli ortalaması ile düzeltilmiştir. Bu prosedür seriler arasında yaklaşık olarak eşit pürüzsüzlük sağlar ve ayrıca her serideki aydan aya değişikliklerin düzensiz hareketlerden ziyade döngüsel olmasından dolayı daha muhtemel olmasını sağlar. Öte yandan, Avrupa komisyonu sisteminde hiçbir komponent serisi düzeltilmemiştir. Bunun etkisi, Almanya dişındaki tüm araştırılan ülkeler için MCD değerini gösteren Ekonomik Duygusal Göstergelere (ESI) yansır (MCD = 1). Bu, yalnızca Almanya için ekonomik duyarlılık göstergesinin döngüsel dönüm noktalarının kolay tanımlanması için yeterince smooth olduğu anlamina gelir.

OECD sisteminde, sadece Birleşik Krallık için CLI, her ay mevcut olan tüm bileşen serileri ile hesaplanmaktadır. Bununla birlikte, Fransa ve Almanya'daki CLI'lerin hesaplanmasında mevcut olan bileşen serilerinin yüzdesi yüzde 80'in üzerinde, ancak İtalya'da yalnızca yüzde 67'dir. İlginç olan, CLI'nin hesaplandığı ay için mevcut olmayan tüm serilerin, ticaret şartları, kayıtlı araçlar ve yeni siparişlerin hacmi gibi niceliksel istatistiksel serilerle ilgili olmasıdır. Öte yandan, tüm finansal ve işletme anketi bileşen serisi, CLI'nin hesaplandığı ay için her zaman kullanılabilir.

EC sisteminin avantajı, tüm bileşenlerin ülkeler arasında bileşik endeksin hesaplanması için her zaman mevcut olmasıdır. Bu, tüm bileşen serilerinin iş anketine ve finansal göstergelere gönderme yaptığı gerçeğiyle açıklanır. Yukarıdaki özete göre, AB Ekonomik Duyarlılık Göstergelerinin her ülkedeki tahmin potansiyelinin nasıl geliştirilebileceği konusunda aşağıdaki sonuçlar çıkarılabilir:

- Her ülkede sadece en iyi performans gösteren bileşen serisi seçin; 
- Parça serilerinin toplanması için eşit bir ağırlıklandırma sistemi kullanin;

- Bileşen serisinin yumuşatılmasi;

- Daha fazla finansal bileşen tanıtılması. 


\section{Kaynakça}

Adamowicz, E., S. Dudek and K. Walczyk 2002. The Use of Business Survey Data in Analyses and Short-term Forecasting, The Case of Poland. Presented at the 26th CIRET Conference, Taipei, October.

Bodo, G., R. Golinelli, and G. Parigi. 2000. Forecasting industrial production in the euro area. Empirical Economics, 25(4), pp.541-561.

Candemir, H.B. and H.B. Karabudak. 1994. The Search for a Business and/or Investment Confidence Index in Turkey. Selected Papers submitted to the 21st Ciret Conference 1993 in Stellenbosch, Studien 48.

Cyert, M. R. 1988. The Economic Theory of Organization and the Firm. New York University Press.

Dengiz, B., and C. Özcan. 1991. İktisadi Yönelim Anketi'nin Geçerliliğinin İncelenmesi Üzerine Bir Çalışma. Quarterly Bulletin of CBRT, 1991/II, pp.183-191.

European Comission 2002. The Joint Harmonised EU Programme of Business and Consumer Surveys, User Guide 2002.

Ferenczi, B. and A. Reiff. 2000. The Role of Survey Data in the Forecasting Performance of Composite Leading Indicators - The Case of Hungarian Industrial Production. Submission to the 25th CIRET Conference, Paris, October.

Gomez, V. and A. Maravall. 1998. Seasonal Adjustment and Signal Extraction in Economic Time Series. Banco de España - Servicio de Estudios Documento de Trabajo n.o 0002.

Moser, C.A. and G. Kalton. 1972. Survey Methods in Social Investigation. 2nd edition, New York, Basic Books.

Nilsson, R. 1999. Business Tendency Surveys and Cyclical Analysis. Business Tendency Surveys, Proceedings of the First Joint

OECD-ADB Workshop, Manila, November. 2000. Confidence Indicators and Composite Indicators. Economic Surveys and Data Analysis, CIRET 
Conference Proceedings, Paris. 2003. Uses of Economic Indicators for Measuring Economic Trends.

OECD/ESCAP Workshop on Composite Leading Indicators and Business Tendency Surveys, 24-26 February 2003, Bangkok.

OECD 1997. Development of Business and Consumer Surveys in Central and Eastern Europe, Summary of Workshops 1991-1996. Transition Economies Division Statistics Directorate, Paris, February.

2000. Cyclical Analysis and Composite Indicators System User Guide, Paris.

2002. Economic Surveys and Data Analysis. CIRET Conference Proceedings, Paris 2000.

2003. Business Tendency Surveys: A Handbook.

Oral, E. 2002. Inflation Expectations on the Basis of Qualitative Surveys. Presented at the 26th CIRET Conference, Taipei, October.

Özdamar, K. 1997. Paket programlar ile İstatistiksel Veri Analizi, Anadolu Üniversitesi, Fen Fakültesi Yayınları.

Pellissier, G.M. 2002. Measuring Business Confidence in South Africa. Presented at the 26th CIRET Conference, Taipei, October.

Sutanto, A. 1999. Business Confidence Index, Consumer Confidence Index and Index of Leading Indicators: An Experiment for Indonesia. Business Tendency Surveys, Proceedings of the First Joint OECD-ADB Workshop, Manila, November.

Yew-Kuang, N. 1992. Business confidence and depression prevention: A Mesoeconomic Perspective. American Economic Review , 82(2), pp.379-385. 